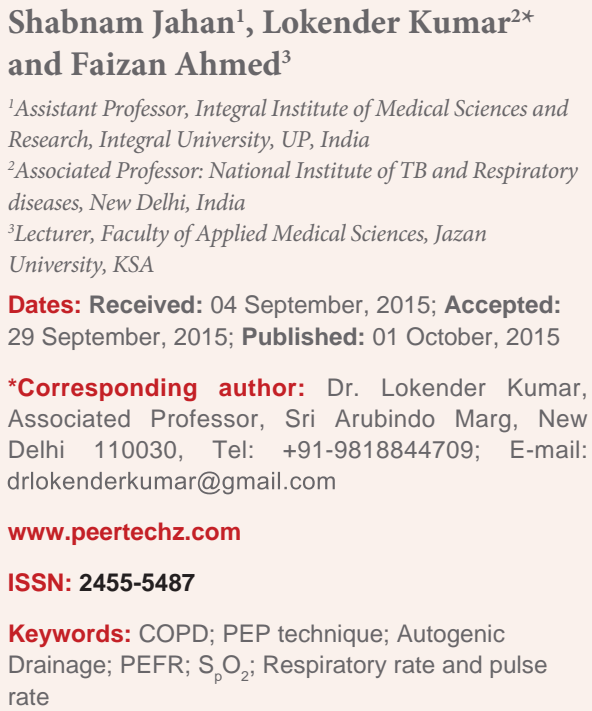

Shabnam Jahan ${ }^{1}$, Lokender Kumar ${ }^{2 \star}$ and Faizan Ahmed ${ }^{3}$

${ }^{1}$ Assistant Professor, Integral Institute of Medical Sciences and Research, Integral University, UP, India

${ }^{2}$ Associated Professor: National Institute of TB and Respiratory diseases, New Delhi, India

${ }^{3}$ Lecturer, Faculty of Applied Medical Sciences, Jazan

University, KSA

Dates: Received: 04 September, 2015; Accepted: 29 September, 2015; Published: 01 October, 2015

*Corresponding author: Dr. Lokender Kumar, Associated Professor, Sri Arubindo Marg, New Delhi 110030, Tel: +91-9818844709; E-mail: drlokenderkumar@gmail.com

www.peertechz.com

ISSN: 2455-5487

Keywords: COPD; PEP technique; Autogenic Drainage; PEFR; $\mathrm{S}_{\mathrm{p}} \mathrm{O}_{2}$; Respiratory rate and pulse rate

\section{Research Article \\ Comparison of Effects of Flutter Device versus Autogenic Drainage on Peak Expiratory Flow Rate, Oxygen Saturation, Respiratory Rate and Pulse Rate in COPD Patients}

\section{Introduction}

Chronic obstructive pulmonary disease (COPD) is a heterogeneous collection of conditions characterized by persistent expiratory airflow limitation [1]. In the Global Burden of Disease Study conducted under the auspices of the WHO and the World Bank, the worldwide prevalence of COPD in 1990 was estimated to be $9.34 / 1,000$ in men and 7.33/1,000 in women. COPD is currently the fourth leading cause of death in the world [2].

Chest physiotherapy is believed to be effective in clearing secretions from the lung of the patients. One of the techniques involves a commercial device called Flutter device. Patrick Althaus, a Swiss physiotherapist, developed the flutter device in Switzerland which is a form of positive expiratory pressure (PEP) in combination with high frequency oscillation that uses oscillating positive expiratory pressure that varies between 10 to $20 \mathrm{~cm} \mathrm{H}_{2} \mathrm{O}$. This device is said to combine a self -regulated oscillating positive expiratory pressure, due to a steel ball, with oscillation of the airflow, and its proposed effects are preventing airway obstruction and removing the accumulation of secretions [3].

In contrast to flutter therapy bronchial secretions are mobilized not only by high frequency oscillation, pressure changes and the air flow changes, but by a special calm breathing technique, called Autogenic drainage which was introduced by Jean Chevaillier in Belgium in 1967. Autogenic drainage (AD), which means "selfdrainage", uses controlled breathing to move mucus. There are three phases of the breathing exercise: "Unsticking" the mucus in the smaller airways by breathing in the base of your lungs, "Collecting" the mucus from the middle airways by breathing at low to mid lung levels, "Evacuating" the mucus from the central airways by breathing at mid to high lung levels [4].

In an earlier comparative study reported between Flutter device and Autogenic Drainage, Skaria et al. [5], found that Flutter device is more effective than the forced expiratory technique i.e. Autogenic Drainage. They reported greater improvement in terms of oxygen saturation and peak expiratory flow rate in the patients of moderate chronic bronchitis, who had used Flutter device. Ernst et al. [6], also did a comparative study between Flutter and AD but on patients of cystic fibrosis. They reported that oscillations applied by Flutter are better capable of decreasing mucus viscoelasticity within the airways as compared to the Autogenic drainage.

Different airway clearance techniques were used for the comparison with the Flutter, which showed inconsistencies in its application, and various outcome measures all contribute to the difficulties in interpreting the literature. We could not find any comparative study of the flutter device and Autogenic drainage in patients with COPD. Thus, the aim of this study was to compare the effectiveness of Flutter device and Autogenic Drainage in COPD patients.

\section{Purpose}

The purpose of this study was toevaluate the effects of short term treatment of Flutter device and Autogenic Drainage (AD) on peak 
expiratory flow rate, oxygen saturation, respiratory rate and pulse rate in patients of Chronic obstructive pulmonary disease(COPD).

\section{Methods}

The study was approved by the institutional research committee as well as the ethical review committee for research studies at National Institute for Tuberculosis and Respiratory Diseases. In the ethical review there were 10-11 members

Patients: Thirty COPD patients including male and female of age group 40 to 60 were included for the study. Coexisting medical problems like Pneumothorax, Hemoptysis, Any Neuromuscular and cardiovascular disorder, Acute Exacerbation of COPD, Acute MI, Respiratory failure patients, Congestive heart failure patients, Patients who has undergone recent thoracic and abdominal surgeries, Any other associated restrictive lung diseases, Hemodynamic instability and Uncooperative patients were excluded from the study.

Intervention: Subjects clinically diagnosed as moderate to severe chronic obstructive pulmonary disease were selected according to inclusion and exclusion criteria and were divided randomly into two experimental groups, as Group A and Group B, consisting of 15 subjects each. A brief explanation about the treatment session was explained to all the subjects.

The treatment duration for both the groups included:

Duration per session: 15-20 minutes / session, No. of sessions per day: Once a day, No. of days per week: 5 Days, Duration of the study: 1 week

The pre and posttest values of peak expiratory flow rate, $\mathrm{O}_{2}$ saturation, Respiratory rate were noted for five days of treatment program. Group A was treated with positive expiratory pressure technique using flutter device and Group B received Autogenic Drainage.

Group A: Flutter Device (Positive expiratory pressure technique) the subjects were asked to seat in a comfortable position leaning forward with elbows supported on a table and neck slightly extended in order to open up the airway. The flutter device was held horizontally and tilted slightly upwards to get maximal oscillatory effect and then it was placed in the mouth. Inspiration was done through the nose. A slow breath in, only slightly deeper than normal with a breath hold of 3-5 seconds was followed by breath out through the flutter device at a slightly faster rate than normal. After 4-8 of these breaths, a deep breath with a 'hold' at full inspiration was followed by a forced expiration through the flutter device. This precipitated expectoration and was followed by a pause for breathing control, and then according to the subjects' preference a cough or huff was done. This process was repeated for 10-15 minutes.

Group B: On the day autogenic drainage was performed patient was advised to sit and relax with neck slightly extended. He was also asked to clear the upper airways (nose or throat) by huffing or blowing nose. The patient began by performing the diaphragmatic breathing at low lung volume inspiration was slow with a pause of three seconds allowing the collateral ventilation, and expiration was done as a sigh with an open glottis and with high velocity as possible but no forced expiration. During this low lung volume breathing, expiration was encouraged to the expiratory reserve volume. When the patient felt secretions to be moving, the volume of inspiration became deeper and expiration did not go down as far as expiratory reserve volume. As the secretions moved up the bronchial tree to the large airways then the patient was asked to perform higher lung volume breathing, tidal volume to inspiratory reserve volume range. This middle to high lung volume breathing continued until the secretions were in the trachea and ready to be expectorated. The patients were taught to suppress the cough, to allow this the cycle of breathing exercise was repeated throughout the 15-20 minutes of treatment session.

\section{Data analysis}

Data analysis was performed using software package of SPSS for windows version 16 (SPSS Inc., U.S.A). Data was tested for the normality of the distribution. Independent sample t-test was used to compare variables between two treatment groups. Repeated measure analysis of variance (ANOVA) was used to examine the changes in all dependent variables within the treatment group. Level of significance set for the study was $95 \%(\mathrm{p}<0.05)$

\section{Results}

Thirty moderate to severe COPD patients (According the GOLD guidelines) were recruited for study after signing the consent form National Institute of Tuberculosis and Respiratory Diseases, New Delhi on the basis of inclusion and exclusion criteria. Out of thirty patients there were $21(70 \%)$ male and $9(30 \%)$ female patients. Out of 30 patients $56.7 \%$ (17) patient were $>50$ years and $43.3 \%$ ( 13) patient were $<50$ years and for the study.

Peak Expiratory Flow Rate (PEFR): There was no significant difference for PEFR while comparing between groups analyses Table 1, Groups A (Flutter) and Group B (Autogenic Drainage). Thus in Group A and Group B the result showed a statistically significant decrease in $\mathrm{p}$ value (with $\mathrm{p}>0.05$ ).

In within group analysis according to Table 2, in group $\mathrm{A}$ (Flutter), when mean value of PEFR which was $130.67 \mathrm{~L} / \mathrm{min}$. of pre dayl was compared with mean value of $150.0 \mathrm{~L} / \mathrm{min}$. of pre day 5 then the result was found to be significant ( $\mathrm{p}=0.0001)$. When mean value of $142.0 \mathrm{~L} / \mathrm{min}$. of post day1 was compared with mean value of $166.67 \mathrm{~L} /$ min. of post day 5 then also the result was found to be significant $(\mathrm{p}=0.001)$.

And within group analysis in group B (Autogenic drainage) Table 2 , when mean value of PEFR which was $150.67 \mathrm{~L} / \mathrm{min}$. of pre day 1 was compared with mean value of $160.0 \mathrm{~L} / \mathrm{min}$. of pre day 5 then result was found to be significant $(\mathrm{p}=0.0001)$. When mean value of $155.0 \mathrm{~L} / \mathrm{min}$. of post day 1 was compared with mean value of $172.67 \mathrm{~L} / \mathrm{min}$. of post day 5 then also the result was found to be significant $(p=0.001)$.Thus in Group A and Group B, the result showed a statistically significant increase in $\mathrm{p}$ value $(\mathrm{p}=0.0001)$

Arterial oxygen saturation $\left(\mathrm{SpO}_{2}\right)$ : While comparing between group analysis Table 3 in Group A and Group B, the result showed a statistically significant decrease in $\mathrm{p}$ value (with $\mathrm{p}>0.05$ ).

In the within group analysis in group A (Flutter), Table 4 when 
Table 1: between group analysis-Peak expiratory flows rates (PEFR)

\begin{tabular}{|c|c|c|c|c|}
\hline PEFR & GROUP-A (Mean+SD) & GROUP-B (Mean+SD) & t- value & -1.349 \\
\hline PEFR1PR & $130.67 \pm 19.445$ & $150.67 \pm 54.046$ & 0.188 \\
\hline PEFR1PO & $142.00 \pm 21.778$ & $155.00 \pm 52.474$ & -0.886 \\
\hline PEFR2PR & $134.67 \pm 26.421$ & $143.33 \pm 46.853$ & -0.624 \\
\hline PEFR2PO & $148.67 \pm 29.244$ & $156.67 \pm 50.943$ & -0.527 \\
\hline PEFR3PR & $142.00 \pm 30.048$ & $152.00 \pm 55.446$ & -0.614 \\
\hline PEFR3PO & $154.00 \pm 29.952$ & $161.33 \pm 57.305$ & -0.439 \\
\hline PEFR4PR & $144.67 \pm 24.746$ & $156.00 \pm 48.961$ & -0.602 \\
\hline PEFR4PO & $156.67 \pm 21.269$ & $163.33 \pm 50.662$ & -0.600 \\
\hline PEFR5PR & $150.00 \pm 35.657$ & $160.00 \pm 50.427$ & -0.470 \\
\hline PEFR5PO & $166.67 \pm 38.110$ & $172.67 \pm 54.963$ & -0.630 \\
\hline
\end{tabular}

Abbreviations: *PEFR1PR-Day1 pre value of peak expiratory flow rate, ${ }^{*}$ PEFR1PO-Day1 post value of peak expiratory flow rate, ${ }^{*} P E F R 2 P R-D a y 2$ pre value of peak expiratory flow rate , ${ }^{*}$ PEFR2PO- Day2 post value of peak expiratory flow rate, ${ }^{*}$ PEFR3PR- Day3 pre value of peak expiratory flow rate , ${ }^{*}$ PEFR3PO- Day3 post value of peak expiratory flow rate, ,PEFR4PR- Day4 pre value of peak expiratory flow rate, ${ }^{*}$ PEFR4PO- Day4 post value of peak expiratory flow rate, ${ }^{*}$ PEFR5PR- Day5 pre value of peak expiratory flow rate, *PEFR5PO- Day5 post value of peak expiratory flow rate.

Table 2: within group analyses-PEFR.

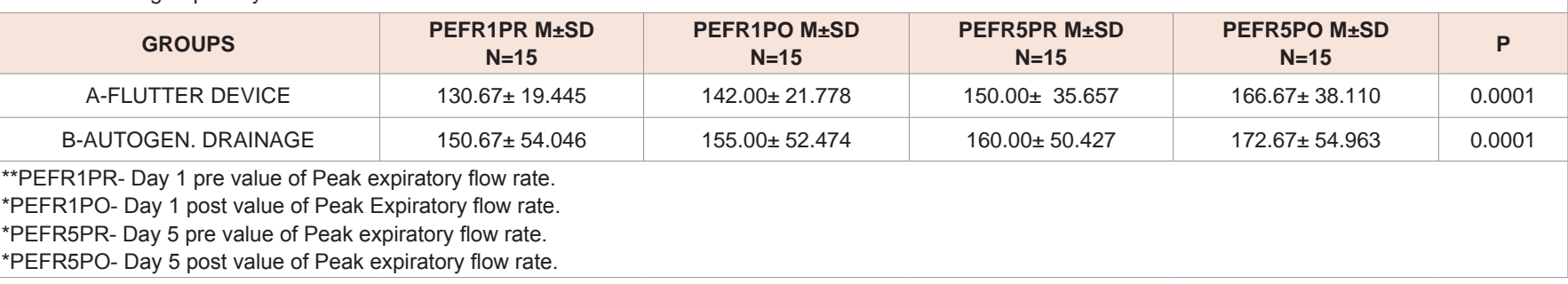

Table 3: between group analyses -Oxygen saturation (SpO2).

\begin{tabular}{|c|c|c|c|c|}
\hline SpO2 & GROUP-A (Mean+SD) & GROUP-B (Mean+SD) & t- value & p-value \\
\hline S1PR & $94.33 \pm 5.538$ & $95.93 \pm 2.764$ & -1.001 & .325 \\
\hline S1PO & $94.20 \pm 5.955$ & $96.07 \pm 3.654$ & -1.035 & .310 \\
\hline S2PR & $95.93 \pm 3.575$ & $96.47 \pm 2.722$ & -.460 & .649 \\
\hline $\mathrm{S} 2 \mathrm{PO}$ & $95.07 \pm 5.763$ & $97.13 \pm 2.134$ & -1.303 & .203 \\
\hline S3PR & $96.47 \pm 2.997$ & $95.53 \pm 3.226$ & .821 & .419 \\
\hline S4PR & $94.73 \pm 6.419$ & $96.07 \pm 3.081$ & -.725 & .474 \\
\hline S4PO & $95.87 \pm 4.291$ & $96.40 \pm 2.746$ & -.405 & .688 \\
\hline S5PR & $95.73 \pm 3.712$ & $95.60 \pm 2.823$ & .111 & .913 \\
\hline S5PO & $95.93 \pm 4.682$ & $96.80 \pm 2.957$ & -.606 & .549 \\
\hline
\end{tabular}

Abbreviations: *S1PR-Day1 pre value of Oxygen saturation ,*S1PO-Day1 post value of Oxygen saturation, *S2PR-Day2 pre value of Oxygen saturation , *S2PODay2 post value of Oxygen saturation, ,'S3PR- Day3 pre value of Oxygen saturation, ,'S3PO- Day3 post value of Oxygen saturation , ${ }^{\star}$ S4PR- Day4 pre value of Oxygen saturation , *S4PO- Day4 post value of Oxygen saturation , ${ }^{*}$ S5PR- Day5 pre value of Oxygen saturation, *S5PO- Day5 post value of Oxygen saturation.

Table 4: within Group Analysis- $\mathrm{SpO}_{2}$.

\begin{tabular}{|c|c|c|c|c|c|}
\hline \multirow{2}{*}{ GROUPS } & S1PR & S1Po & \multirow{2}{*}{$\begin{array}{c}\text { S5PR } \\
M \pm S D ~ N=15\end{array}$} & \multirow{2}{*}{$\begin{array}{c}\text { S5PO } \\
M \pm S D ~ N=15\end{array}$} & \multirow[b]{2}{*}{$\mathbf{P}$} \\
\hline & $\mathrm{M} \pm \mathrm{SD} \quad \mathrm{N}=15$ & $\mathrm{M} \pm \mathrm{SD} \quad \mathrm{N}=15$ & & & \\
\hline A-FLUTTER DEVICE & $94.33 \pm 5.538$ & $94.20 \pm 5.955$ & $95.73 \pm 3.712$ & $95.93 \pm 4.682$ & 0.0001 \\
\hline B-AUTOGENIC DRAINAGE & $95.93 \pm 2.764$ & $96.07 \pm 3.654$ & $95.60 \pm 2.823$ & $96.80 \pm 2.957$ & 0.0001 \\
\hline \multicolumn{6}{|c|}{$\begin{array}{l}\text { *S1PR-Day } 1 \text { pre value of Oxygen saturation. } \\
\text { *S1PO-Day } 1 \text { post value of oxygen saturation. } \\
\text { *S5PR-Day } 5 \text { pre value of oxygen saturation. } \\
\text { *S5PO-Day } 5 \text { post value of oxygen saturation. }\end{array}$} \\
\hline
\end{tabular}


mean value of $\mathrm{SpO}_{2}$ which was $94.33 \%$ of pre day1 was compared with mean value of $95.73 \%$ of pre day 5 then result was found to be significant ( $\mathrm{p}=0.0001$ ). When mean value of $94.20 \%$ of post day 1 was compared with mean value of $95.93 \%$ of post day 5 then also the result was found to be significant $(\mathrm{p}=0.001)$.

whereas within group analysis in group B (Autogenic drainage), Table 4 when mean value of $\mathrm{SpO}_{2}$ which was $95.93 \%$ of pre day1 was compared with mean value of $95.60 \%$ of pre day 5 then result was found to be significant $(\mathrm{p}=0.0001)$. When mean value of $96.07 \%$ of post dayl was compared with mean value of $96.80 \%$ of post day 5 then also the result was found to be significantly increase $(p=0.001)$ as in group $\mathrm{A}$.

Respiratory Rate (RR): between group analysis Table 5. There was no significant difference found while comparing Groups A (Flutter) and Group B (Autogenic Drainage) with p >0.05 .

Within group analysis showed a statistically highly significant result ( $\mathrm{p}=0.0001$ ) Table 6 . In the within group analysis in group A (Flutter), when mean value of RR which was $27 \mathrm{bpm}$ of pre day1 was compared with mean value of $28.33 \mathrm{bpm}$ of pre day 5 then result was found to be significant ( $p=0.0001$ ). When mean value of $29.07 \mathrm{bpm}$ of post dayl was compared with mean value of $29.33 \mathrm{bpm}$ of post day 5 then the result was found to be significantly increase in $\mathrm{p}$ value $(\mathrm{p}=0.001)$.

In the within group analysis in group B Table 6 (Autogenic drainage), when mean value of RR which was $26.73 \mathrm{bpm}$ of pre day1 was compared with mean value of $27.93 \mathrm{bpm}$ of pre day 5 then the result was found to be significant $(\mathrm{p}=0.0001)$. When mean value of

Table 5: between group analysis- Respiratory Rate (RR).

\begin{tabular}{|c|c|c|c|c|}
\hline $\mathbf{R R}$ & GROUP-A (Mean+SD) & GROUP-B (Mean+SD) & t- value & p-value \\
\hline RR1PR & $27.00 \pm 6.036$ & $26.73 \pm 7.285$ & .109 & .914 \\
\hline RR2PR & $27.60 \pm 5.841$ & $26.53 \pm 5.317$ & .523 & .605 \\
\hline RR2PO & $28.00 \pm 5.438$ & $26.27 \pm 5.483$ & .869 & .392 \\
\hline RR3PO & $27.40 \pm 5.262$ & $27.40 \pm 5.717$ & 0.000 & 1.000 \\
\hline RR4PR & $27.07 \pm 4.317$ & $28.00 \pm 6.612$ & -0.458 & 0.651 \\
\hline RR4PO & $28.93 \pm 5.444$ & $28.47 \pm 6.186$ & 0.219 & 0.828 \\
\hline RR5PR & $28.33 \pm 4.685$ & $27.93 \pm 6.617$ & 0.191 & 0.850 \\
\hline RR5PO & $29.33 \pm 5.473$ & $28.07 \pm 6.181$ & 0.594 & 0.557 \\
\hline
\end{tabular}

Abbreviations: *RR1PR-Day1 pre value of Respiratory Rate, ${ }^{*} \mathrm{RR} 1 \mathrm{PO}-\mathrm{Day} 1$ post value of Respiratory Rate, ${ }^{*} \mathrm{R} 2 \mathrm{PR}-\mathrm{D} a y 2$ pre value of Respiratory Rate, ${ }^{\star} \mathrm{RR} 2 \mathrm{PO}$ Day2 post value of Respiratory Rate, *RR3PR- Day3 pre value of Respiratory Rate, *RR3PO- Day3 post value of Respiratory Rate, *RR4PR- Day4 pre value of Respiratory Rate, *RR4PO- Day4 post value of Respiratory Rate, ${ }^{*} R R 5 P R-$ Day5 pre value of Respiratory Rate, *RR5PO- Day5 post value of Respiratory Rate.

\begin{tabular}{|c|c|c|c|c|c|}
\hline \multirow{2}{*}{ GROUPS } & RR1PR & RR1PO & \multirow{2}{*}{$\begin{array}{l}\text { RR5PR M } \pm S D \\
\quad N=15\end{array}$} & \multirow{2}{*}{$\begin{array}{l}\text { RR5PO M } \pm S D \\
\quad N=15\end{array}$} & \multirow{2}{*}{$\mathbf{P}$} \\
\hline & $\mathrm{M} \pm \mathrm{SD} \quad \mathrm{N}=15$ & $\mathrm{M} \pm \mathrm{SD} \quad \mathrm{N}=15$ & & & \\
\hline A-FLUTTER DEVICE & $27.00 \pm 6.036$ & $29.07 \pm 5.885$ & $28.33 \pm 4.685$ & $29.33 \pm 5.473$ & 0.0001 \\
\hline B-AUTOGENIC DRAINAGE & $26.73 \pm 7.285$ & $27.67 \pm 6.366$ & $27.93 \pm 6.617$ & $28.07 \pm 6.181$ & 0.0001 \\
\hline \multicolumn{6}{|c|}{$\begin{array}{l}\text { *RR1PR-Day } 1 \text { pre value of Respiratory rate. } \\
\text { * *RR1PO-Day } 1 \text { post value of Respiratory rate. } \\
\text { * *RR5PR-Day } 5 \text { pre value of Respiratory rate. } \\
\text { *RR5PO-Day } 5 \text { post value of Respiratory rate. }\end{array}$} \\
\hline
\end{tabular}

$27.67 \mathrm{bpm}$ of post day1 was compared with mean value of $28.07 \mathrm{bpm}$ of post day 5 then also the result was found to be significant $(\mathrm{p}=0.001)$ as in group A.

Pulse Rate (PR): between group analysis Table 7 No significant difference was found while comparing Groups A (Flutter) and Group B (Autogenic Drainage) with $\mathrm{p}>0.05$.

Within group analysis found a statistically highly significant result $(\mathrm{p}=0.0001)$ Table 8 . In the within group analysis in group A (Flutter), when mean value of PR which was 99.33 beats per minute of pre day1 was compared with mean value of 104.40 beats per minute of pre day 5 then result was found to be significant ( $\mathrm{p}=0.0001$ ). When mean value of 104.13 beats per minute of post day1 was compared with mean value of 106.40 beats per minute of post day 5 then the result was found to be significantly increase in $\mathrm{p}$ value $(\mathrm{p}=0.001)$.

As per Table 8 in the within group analysis in group B (Autogenic drainage), when mean value of $P R$ which was 101.53 beats per minute of pre day1 was compared with mean value of 103.33 beats per minute of pre day 5 then result was found to be significant ( $\mathrm{p}=0.0001$ ). When 
Table 7: Between group analyses- Pulse Rate (PR).

\begin{tabular}{|c|c|c|c|c|}
\hline PR & GROUP-A (Mean+SD) & GROUP-B (Mean+SD) & t- value & p-value \\
\hline P1PR & $99.33 \pm 15.253$ & $101.53 \pm 6.988$ & -0.508 & 0.616 \\
\hline P1PO & $104.13 \pm 16.137$ & $104.33 \pm 10.688$ & -0.040 & 0.968 \\
\hline P2PR & $100.27 \pm 12.629$ & $102.13 \pm 7.945$ & -0.485 & 0.632 \\
\hline $\mathrm{P} 2 \mathrm{PO}$ & $104.67 \pm 14.401$ & $101.73 \pm 10.039$ & 0.647 & 0.523 \\
\hline P3PR & $101.27 \pm 10.872$ & $105.20 \pm 9.359$ & -1.062 & 0.297 \\
\hline P3PO & $107.00 \pm 13.722$ & $104.87 \pm 9.561$ & 0.494 & 0.625 \\
\hline P4PR & $104.60 \pm 13.932$ & $101.33 \pm 8.423$ & 0.777 & 0.444 \\
\hline P4PO & $107.40 \pm 12.552$ & $102.00 \pm 9.457$ & 1.331 & 0.194 \\
\hline P5PR & $104.40 \pm 14.446$ & $103.33 \pm 13.383$ & 0.210 & 0.835 \\
\hline P5PO & $106.40 \pm 14.045$ & $103.47 \pm 9.913$ & 0.661 & 0.514 \\
\hline
\end{tabular}

Abbreviations: *P1PR-Day1 pre value of Pulse Rate, ${ }^{\star} \mathrm{P} 1 \mathrm{PO}-\mathrm{Day} 1$ post value of Pulse Rate, ${ }^{\star} \mathrm{P} 2 \mathrm{PR}-\mathrm{Day} 2$ pre value of Pulse Rate, ${ }^{\star} \mathrm{P} 2 \mathrm{PO}-\mathrm{Day} 2$ post value of Pulse Rate, ${ }^{\star} \mathrm{P} 3 \mathrm{PR}$ - Day3 pre value of Pulse Rate, ${ }^{\star} \mathrm{P} 3 \mathrm{PO}-\mathrm{Day} 3$ post value of Pulse Rate, ${ }^{\star} \mathrm{P} 4 \mathrm{PR}-\mathrm{Day} 4$ pre value of Pulse Rate, ${ }^{*}$ 4PO- Day4 post value of Pulse Rate, *P5PR- Day5 pre value of Pulse Rate, ${ }^{*}$ P5O- Day5 post value of Pulse Rate.

Table 8: Within Group Analyses-Pulse Rate.

\begin{tabular}{|c|c|c|c|c|c|}
\hline GROUPS & \begin{tabular}{ll}
\multicolumn{2}{c}{ P1PR } \\
$M \pm S D \quad N=15$
\end{tabular} & $\begin{array}{l}\mathrm{P} 1 \mathrm{PO} \\
\mathrm{M} \pm \mathrm{SD} \\
\mathrm{N}=15\end{array}$ & $\begin{array}{r}\text { P5PR } \\
M \pm S D \\
N=15\end{array}$ & $\begin{array}{l}\mathrm{P} 5 \mathrm{PO} \\
\mathrm{M} \pm \mathrm{SD} \\
\mathrm{N}=15\end{array}$ & $\mathbf{P}$ \\
\hline A-FLUTTER DEVICE & $99.33 \pm 15.253$ & $104.13 \pm 16.137$ & $104.40 \pm 14.446$ & $106.40 \pm 14.045$ & 0.0001 \\
\hline B-AUTOGENIC DRAINAGE & $101.53 \pm 6.988$ & $104.33 \pm 10.688$ & $103.33 \pm 13.383$ & $103.47 \pm 9.913$ & 0.0001 \\
\hline $\begin{array}{l}\text { *P1PR-Day } 1 \text { pre value of Pulse rate. } \\
\text { *P1PO-Day } 1 \text { post value of Pulse rate. } \\
\text { *P5PR-Day } 5 \text { pre value of Pulse rate. } \\
\text { *P5PO-Day } 5 \text { post value of Pulse rate }\end{array}$ & & & & & \\
\hline
\end{tabular}

mean value of 104.33 beats per minute of post day1 was compared with mean value of 103.47 beats per minute of post day 5 then also the result was found to be significant $(\mathrm{p}=0.001)$ as in group A.

\section{Discussion}

This study was designed to compare the effectiveness of Flutter device and Autogenic Drainage on Peak expiratory flow rate (PEFR), Arterial oxygen saturation $\left(\mathrm{SpO}_{2}\right)$, Respiratory rate (RR) and Pulse rate (PR) in COPD patients. In order to deal with such a condition, many treatment methods are currently in vogue, thus we are in emergent need of applying the correct technique that suits the patient's need. The growing demand for meeting various problems that are associated with pulmonary complications are indeed worth considering. This study was designed as a randomized crossover trial two groups pretest and posttest study.

Patients diagnosed with moderate to severe chronic obstructive pulmonary disease (COPD) according to (the GOLD classification), were recruited for this study. During the recruitment program 30 patients entered the program after signing the consent form with mean age of $52.67 \pm 6.287$ years in group A and in Group B of 50.13 \pm 7.060 years. Total of 30 patients were analyzed for the dependent variable which matches the sample size of the study. The result of this study showed that the effects of the treatment with Flutter and $\mathrm{AD}$ in COPD patients on PEFR, $\mathrm{SpO}_{2}, \mathrm{RR}$ and $\mathrm{PR}$ had a statistically highly significant effect $(\mathrm{p}=0.0001)$ according to within group comparison and in between groups comparison no significant changes $(p>0.05)$ were found on these variables.

\section{PEFR}

In the within group analysis in group A (Flutter) and group B (AD) the result was found to be significant (0.0001). In 2009 Richa et al. [7], conducted a study using flutter device for 3 days of treatment program in 15 COPD patients. On comparing the results of day 1 morning with day 3 evening, they found significant change in PEFR group (0.0001). These findings support the findings of the present study. The reasons might be that both the studies are similar in terms of including COPD patients and physiological working of flutter as oscillating low PEP device.

Savci et al. [8], also found the similar findings on stable COPD patients using $\mathrm{AD}$ technique for 20 days of period they found similar significant change in PEFR. The result of this study supported our study because both the studies included airflow limitation conditions which can show improvement in PEFR by the use of $\mathrm{AD}$ technique.

\section{Oxygen saturation $\left(\mathrm{SpO}_{2}\right)$}

In the within group analysis in group A (Flutter) and group B (Autogenic Drainage), the result was found to be significant (0.0001). A study was conducted by Moiz et al. [9], who used Autogenic drainage in acute exacerbation of COPD. In their study they demonstrated a significant improvement in oxygen saturation in comparison to ACBT. Mean $\mathrm{SpO}_{2}$ immediately after AD was $94.2 \%$ 
which was statistically significant (0.043). Present study also found significant improvement in $\mathrm{SpO}_{2}(\mathrm{p}=0.0001)$. This observation may be due to increased alveolar ventilation and $\mathrm{CO}_{2}$ washout resulting out of hyperventilation which could have been an effect of diaphragmatic breathing at different lung volumes.

Smibi Skaria et al. [5], also compared the effect of positive expiratory pressure technique (flutter) over Autogenic Drainage technique in 30 chronic bronchitis patients. The treatment was carried out in each of 2 sessions per day for 5 days of total 2 weeks. They observed significant change for oxygen saturation at $\mathrm{p}<0.05$ and the present study also found significant change at $p=0.0001$ which is compatible with our study. The reasons might be because of same age group (40 to 60 yrs.) and airflow limitation condition patients.

\section{Respiratory rate (RR)}

In the within group analysis in group A (Flutter) and group B (Autogenic Drainage), the result was found to be significant (0.0001). According to Richa et al. [7], study who used flutter device in 15 COPD patients for 3 days and they found significant results when they compared day 1 treatment with day 3 with p value of 0.03 , which is compatible with the present $\operatorname{study}(\mathrm{p}=0.0001)$. This compatibility might be due to almost same treatment sessions ( 6 sessions by their study and 5 sessions by the present study) and same COPD conditions.

\section{Pulse rate/Heart rate (PR/HR)}

In the within group analysis in group A (Flutter) and group B (Autogenic Drainage) the result was found to be significant ( $\mathrm{p}=0.0001)$. Moiz et al. [9], conducted a study using Autogenic drainage technique in cases of acute exacerbation of COPD. In their study they demonstrated a significant difference with $\mathrm{p}=0.043$ which matches with the significant result $(\mathrm{p}=0.001)$ of present study that can be explained by the theory that at low level of the exercise Considerable increase in heart rate / Pulse rate is almost exclusively via vagal withdrawal with little evidence for systemic increases in sympathetic nerve activity until the exercise intensity is at or above the maximal steady state.

In between group analysis, no significant differences were observed in group A and group B for all the four variables; PEFR, $\mathrm{SpO}_{2}, \mathrm{RR}$ and PR. Therefore, superiority of any of them cannot be ascertained. The selection of the individual technique or device for the same purpose should rely on other factors like convenience of the subjects, personal preferences etc. Duration of the study is also a major factor in bringing insignificant results, as the present study was of short duration including only five days in a week with only one session of 15 minutes in a day.

The study done by Smibi Skaria et al. [5], who compared flutter with Autogenic drainage technique in chronic bronchitis condition. They found significant results with $\mathrm{p}<0.05$ for oxygen saturation and peak expiratory flow rate respectively. They stated that there is better effectiveness when positive expiratory pressure technique was given using flutter device than Autogenic drainage in chronic bronchitis patients when each of two sessions per day was given for two weeks. This was in agreement with the study by Konstan et al. [10], who found a significant change with flutter therapy compared with conventional chest physiotherapy. They gave the reason that this might be due to improved cough clearance by keeping the airways open during lightly forced expiration, through the added positive airway pressure produced during expiration. The shear rates during such a cough maneuver, with the consequent flow and pressure changes, have to be high enough to move bronchial secretions, but not so high that airway collapse occurs. Whereas, our study shows insignificant results when between groups comparisons were made, this might be because of our short duration treatment effect of only one session per day.

Thus, we presume with this study that the effectiveness of treatment given to the patient can be better analyzed when long term treatment protocol is included and it might be helpful to judge the effectiveness of treatment given to the patients. These techniques can be used in COPD according to patient's and the physiotherapist's preferences. Present study is limited by small sample size, age group of between 40-60 years, moderate to severe COPD patients, including only two airway clearance techniques like Positive expiratory pressure technique (flutter device) and Forced expiratory technique (Autogenic drainage) to detect it effects on COPD patients and is limited to short term outcomes; results may not be applicable to long term outcomes such as disease progression and quality of life.

\section{Conclusion}

The results of this study indicate that flutter is as effective as the Autogenic drainage in improving peak expiratory flow rate, $\mathrm{SpO}_{2}$, respiratory rate and pulse rate in COPD patients. This study therefore concludes that both techniques can be used with equal effectiveness in COPD patients and the choice may be guided by the patient and the physiotherapist preference.

\section{References}

1. John F Murray, Jay A Nadel (2010) Murray and Nadels Textbook of Respiratory Medicine, 5 Edition ISBN: 978-1-4557-3383-5.

2. Pauwels RA, Buist AS, Calverley PM, Jenkins CR, Hurd SS et al. (2001) Global strategy for the diagnosis, management, and prevention of chronic obstructive pulmonary disease. NHLBI/WHO Global Initiative for Chronic Obstructive Lung Disease (GOLD) Workshop summary, Am J Respir Crit Care Med 163: 1256-1276.

3. Bellone A, Lascioli R, Raschi S, Guzzi L, Adone R (2000) Chest physical therapy in patients with an acute exacerbation of chronic bronchitis: effectiveness of three methods. Arch Phys Med Rehabil 81: 558-560.

4. Pryor JA, Webber BA (2000) Physiotherapy and paramedical issues. In: Hodson ME, Geddes D, editors. Cystic Fibrosis. 2nd ed.

5. Smibi Skaria, Arun J, Sethi J (2008) Effect of positive expiratory press. tech. over forced expiratory tech. on bronchial hygiene in patients with moderate chronic bronchitis. Indian Journal of Physiotherapy and Occupational Therapy 2:

6. App EM, Kieselmann R, Reinhardt D, Lindemann H, Dasgupta B, et al. (1998) Sputum Rheology changes in cystic fibrosis lung disease following two different types of physiotherapy: flutter versus autogenic drainage. Chest 114: 71-77.

7. Richa, Rajeev Aggarwal, Md Abu Shaphe, Chacko George, Anurag Vats (2010) A comparison of flutter device and active cycle of breathingtechniques in acute exacerbation of chronic obstructive pulmonary disease patients. Indian Jouanl of Physiotherapy and Occupational Therapy 4: 60-64.

8. Savci S, Ince DI, Arikan H (2000) A comparison of autogenic drainage and 
the active cycle of breathing techniques in patients with chronic obstructive pulmonary disease. J Cardiopulm Rehabil 20: 37-43.

9. Jamal Ali Moiz, Kamal Kishore, Belsare DR (2007) A comparison of autogenic drainage and active Cycle of breathing technique in patients with acute exacerbation of COPD 1:

10. Konstan MW, Stern RC, Doershuk CF (1994) Efficacy of the flutter device for airway mucus clearance in patients with cystic fibrosis. Paediatrics 124: 689693.

Copyright: (c) 2015 Jahan S, et al. This is an open-access article distributed under the terms of the Creative Commons Attribution License, which permits unrestricted use, distribution, and reproduction in any medium, provided the original author and source are credited.

Citation: Jahan S, Kumar L, Ahmed F (2015) Comparison of Effects of Flutter Device versus Autogenic Drainage on Peak Expiratory Flow Rate, Oxygen 